\title{
ENTRE JOVENS EDUCADORAS NEGRAS E SUAS FORMAS DE ATIVISMO: POR OUTRA PRÁXIS EMANCIPATÓRIA
}

As relações raciais no Brasil podem ser entendidas como um "descritor", uma "área de investigação", uma questão ampla e consequentemente, transversal. Aparece também como uma inspiração para a análise das desigualdades diversas. E se assim pudermos considerar, os estudos sobre Educação para as Relações Raciais podem ser avaliados como um eixo fundamental para quem deseja entender a gênesis de uma sociedade que sofreu e ainda se inspira na experiência da colonização.

Chama a atenção o trabalho de Luane Bento dos Santos (2011) sobre as estratégias de mulheres negras, inseridas no nível superior para construírem suas identidades como sujeito coletivo. Seu esforço intelectual nos conduziu a novos achados igualmente importantes quando pensamos o leque de opções para sair do lugar inicial de indivíduo, parte de uma família nuclear. A abordagem apresentada na pesquisa de Santos (Ibidem) realça o sentido dado ao pertencimento e dedica-se a analisar as opções estéticas com o foco na cultura das tranças, do cabelo Black Power e assim, nos orienta na análise sobre esse espaço/tempo ocupado por jovens negras em formação superior. Aborda, também, alguns aspectos sobre as trajetórias - nuances relacionadas ao conflito racial que provocaram uma identificação também pela experiência de enfrentamento por conta do fenômeno do racismo.

Antes de tudo, tratar o protagonismo de mulheres negras ativistas e jovens, significa entender seus modos de traduzir um mosaico de coisas já denunciadas e que se relacionam com as heranças da colonização. As resistências, as possibilidades de fortalecimento fazem parte de um jogo de identificação nesses espaços definidos pelos coletivos. E essa situação sugere a seguinte questão:

É preciso levar em consideração que os modos de uso sobre os cabelos da cabeça estão embutidos em sistemas de relações sociais em todas as culturas. Eles sempre dizem alguma coisa seja de natureza institucional, religiosa, sexual, de classe ou de opressão como no caso dos africanos escravizados. Por esse motivo, levar em consideração a importância do cabelo crespo para negros e negras é considerar que, como em qualquer cultura, as populações negras brasileiras descendentes de povos africanos carregavam consigo valores, histórias, hábitos culturais que passaram por processos de esvaziamento e perseguição. Mas que, incrivelmente, preservaram alguns traços e hábitos até os dias de hoje como o caso dos cuidados com o cabelo através das técnicas consideradas "afro". Tradições e hábitos revistos (SANTOS, 2010, p.34). 
Consideramos que, a estética e 'manipulação do cabelo' (LUCINDA, 2005; GOMES, 2002) e/ou do corpo como um todo (ALMEIDA, 2005; FACCHINI, 2008) nos ajuda a problematizar o processo de colonização/descolonização do corpo através da padronização branca e heterossexual. Com isso, é importante sublinhar que cabelo e corpo não estão em situações opostas, pelo contrário, se complementam na construção de uma identidade de resistência. Lucinda nos ajuda a entender essa afirmação da identidade, positivando a estética através do uso da trança ao dizer que

A trança tem um fim em si mesmo e, ao mesmo tempo, cumpre um resultado, qual seja: resignificar aquela parte do corpo negro que, depois da pele, é o principal alvo de discriminação: o cabelo. Deste modo, contribui para o empoderamento de sujeitos sociais, mormente mulheres, favorecendo uma autoestima autêntica e um autoconceito positivo. Trata-se de uma forma de reinventar o corpo negro (LUCINDA, 2005, p.116).

Seguindo essa discussão de protagonismos e resistências, Marcelino (2011) faz uma reflexão em sua dissertação de mestrado sobre "mulheres negras", cuja orientação sexual rompe com o padrão hegemônico estabelecido. A sexualidade, o gênero e a raça se intercruzam e estabelecem outras buscas de enfrentamentos diante do racismo patriarcal e da lesbofobia. Em algumas situações verificou-se que na díade racismo-lesbofobia, a questão da discriminação será mais contundente, quanto mais "escura" for a cor da pele e mais "masculinizada" se apresentar. Essa configuração de lugares sociais e raça terá uma forte implicância no sujeito 'mulher negra' dentro da sociedade, na relação com o sexo oposto e na construção da identidade. Ao se tratar de mulheres negras e suas lutas, seja no âmbito individual ou coletivo, o protagonismo de suas ações sempre estiveram presentes num processo contínuo de trazer à tona suas demandas.

A carga de invisibilidade e a ausência em diferentes espaços não impossibilitou a chegada e a presença da mulher negra enquanto sujeito em construção na sociedade brasileira. Chamamos aqui de 'sujeito em construção' porque a identidade "mulher negra" é o resultado de ações políticas, identitárias, de resistência e de sobrevivência que ao longo de toda a trajetória dos/as negros/as na história da sociedade brasileira, essas mulheres protagonizaram experiências e representações frente às diversidades e às desigualdades impostas. Por tudo isso, podemos afirmar que, a participação das mulheres negras enquanto ativistas nas lutas políticas, culturais e religiosas vem contribuindo para o fortalecimento e para se conceber outros processos de identificação racial em diferentes espaços educativos - formais e nãoformais, conforme tem acentuado Miranda (2013).

Nessas últimas décadas, acompanhamos algumas transições onde a centralidade está na participação dessas interlocutoras. A presença dessas personagens está associada ao avanço 
de diferentes movimentos que vem rompendo os lugares da subalternidade reservados aos não estabelecidos $^{i i}$. Indo ao encontro de uma práxis emancipatória, as educadoras chamam nossa atenção pelas iniciativas que vimos acontecer indo além da instituição escolar. É nessa perspectiva que iremos compartilhar as práticas e as formas de atuações de dois coletivos de mulheres negras do Rio de Janeiro: Coletivo Meninas Black Power e Associação de Mulheres Negras Aqualtune.

\section{Organizações de mulheres negras: uma breve contextualização}

Historicamente, a participação das mulheres nas esferas sociais é resultado da tomada de consciência e da ousadia tendo em vista os enfrentamentos assumidos nesse ir e vir tão marcado pelas forças do patriarcado. Inúmeras associações foram criadas e assumiram parcerias fundamentais para a garantia de direitos fundamentais. Estamos chamando a atenção para os espaços e as configurações desestabilizadoras do staus quo.

As exigências que essas associações passaram a fazer deram resultados também históricos como, por exemplo, a garantia dos direitos de voto, de participação política, de educação formal, de trabalho, de controle do corpo -, opção pela maternidade ou não - e de autonomia individual, entre tantas outras demandas. Essas questões trouxeram à tona discussões sobre a subalternidade feminina, que durante séculos permearam a sociedade brasileira e a sua decorrente invisibilização. Com estas pautas, o movimento feminista contribuiu para transformar as experiências de vida, principalmente, das mulheres brancas e heterossexuais brasileiras. Com esse apanhado, temos alguns pontos relevantes sobre como é imprescindível não dispensarmos os avanços históricos quando o tema é a luta feminina.

Por outra parte, o feminismo negro nasce na década de 1970, nos Estados Unidos através de grupos de mulheres negras que passam a questionar as teorias feministas, as quais privilegiam um discurso homogêneo que invisibiliza a diversidade das mulheres dentro do movimento feminista até então consolidado. Quanto à mulher negra, suas pautas políticas mais específicas tomaram muito mais tempo para serem colocadas, principalmente devido ao fato de que estas, na sua maioria, não tinham acesso à educação de nível superior, cenário no qual o movimento feminista mais avançou no Brasil a partir dos anos 1970. Por outro lado, os limites impostos a sua autonomia, a sua visibilidade e ao controle das pautas políticas da militância negra no Brasil pelos indivíduos do sexo masculino foram razões que levaram muitas mulheres negras a se afastarem também do movimento negro brasileiro. Os discursos de igualdade proferidos tanto pelo movimento negro como pelo movimento feminista, acaba 
por não agregar as especificidades desse segmento de mulheres. As rupturas com esses dois movimentos tornam-se importantes para a (re)organização de um novo movimento de mulheres que tratará em suas agendas políticas, as opressões inseridas nas variáveis de gênero e raça como constituintes do fosso das desigualdades em detrimento da mulher negra frente ao homem branco, a mulher branca, o homem negro.

No Brasil, essa discussão ganha força a partir da década de 1980, protagonizado por algumas feministas negras, entre elas, destacamos Lélia Gonzalez que problematiza as opressões e os lugares diferenciados vividos pelas mulheres negras. A partir do cenário dos movimentos negro e feminista, Ribeiro (1995) resgata a participação das mulheres negras em ambos os movimentos desmistificando a suposta igualdade entre as mulheres, que colocou as negras como sujeitos implícitos. A crítica das mulheres negras tidas inicialmente como radicais se tornaram alavancas de mudanças e de organização das próprias mulheres negras. Diante disso, vários grupos começam a se organizar em todo o país atuando em diversos eixos, tais como: educação, saúde, identidade racial, sexualidade entre outros.

Através da luta do movimento de mulheres negras, as iniciativas as levaram a passos importantes, resultando em uma maior participação política. Destacamos como grandes ações: o I Encontro de Mulheres Negras em 1988; a V Conferência sobre as Mulheres em 1995 (Beijing) e a III Conferência Mundial contra o Racismo, a Discriminação Racial, a Xenofobia e as Formas Conexas de Intolerância em 2001 (Durban). Não podemos esquecer que a Constituição Federal de 1988 potencializou 80\% das demandas das mulheres. No que tange à situação da mulher negra, o distanciamento da realidade vivida por esse segmento impulsionou questões específicas, protagonizando assim uma trajetória de lutas e resistências que mudaram o cenário até então constituído.

\section{O fazer dos Coletivos 'Meninas Black Power' e "Aqualtune"}

Os passos do protagonismo das mulheres negras vêm de longe. Protagonizar é atuar de forma participativa e construtiva em prol de um objetivo. Nas últimas décadas, a sociedade brasileira tem acompanhado o crescimento de diversos coletivos, cuja atuação tem sido cada vez mais sistemática em diferentes espaços e visibilidade. No campo da educação, por exemplo, esse diálogo tem ganhado corpo através da presença de alguns desses grupos. Inegavelmente, vem contribuindo e desenvolvendo práticas educativas numa perspectiva voltada para o respeito às diferenças frente às diversidades e o empoderamento dos sujeitos. 
No início desse texto, nos referimos a compartilhar as estratégias e os protagonismos educativos de dois coletivos com atuações na cidade do Rio de Janeiro. O interesse pela escolha se deu através de alguns pontos comuns entre os dois. Vejamos: (a) São formados por mulheres jovens negras; (b) Tem como objetivo discutir as diferentes formas como o racismo se apresenta em interconexão com outros fenômenos, tais como o machismo, a homofobia, o patriarcalismo; (c) Suas ações são de cunho educativo, voltadas para a formação do pensamento crítico e empoderamento dos sujeitos; e (d) Atuam em espaços 'não-formais' e principalmente em espaços formais, como escolas e universidades.

A sociedade brasileira tem acompanhado nas últimas décadas, a atuação cada vez maior de grupos que demandam o reconhecimento das diferenças no espaço escolar, entre elas, a gênero, étnicas, sexual e religiosa. Tanto no campo normativo ${ }^{\mathrm{iii}}$, como nas práticas pedagógicas $^{\text {iv }}$. A educação brasileira tem se defrontado com o desafio de se transformar: deixar de negar física ou simbolicamente esse "outro/a" para propor dinâmicas que impactem o fazer educativo. Como bem nos lembra Miranda (2003, p.103), "os muros da instituição escolar são interpretados como um dos mais importantes obstáculos nos processos de descolonização do conhecimento".

Há várias décadas, diferentes coletivos organizados conectados ao movimento negro no país, vem denunciando injustiças, desigualdades e discriminações, reivindicando igualdade de acesso a bens e serviços, reconhecimento político e cultural na educação escolar, nos currículos escolares, nos cursos de formação inicial e continuada de professores. $\mathrm{O}$ coletivo "Meninas Black Power" é um desses grupos. Esse coletivo é formado por mulheres pretas com formação em diferentes áreas, que optaram pelo cabelo crespo natural e compreendem os significados e significantes dele na sociedade. Começou sua trajetória primeiramente na rede social Orkut, depois migrou para o blog e criaram uma fan page no Facebook. Além dos canais de comunicação, o coletivo promove encontros como Encrespando ${ }^{\mathrm{v}}$.

A escola como um palco das diversidades tornou-se um dos campos de atuação desse coletivo, visando estreitar o diálogo e a distância entre a cultura e realidade escolar e os movimentos sociais, através de ações semanais em escolas públicas da Baixada Fluminense, como por exemplo, em Tinguá, bairro de Nova Iguaçu, no estado do Rio de Janeiro. A partir de 2013, iniciaram um trabalho junto às escolas públicas e privadas levando propostas pedagógicas ou projetos de intervenção para se trabalhar os conteúdos pertinentes à LDB 9.394/96, que estabelece através da alteração dos artigos 26-A; 79-A e 79-B, a obrigatoriedade do ensino da temática de História da África e afro-brasileira nos 
estabelecimentos de ensino. Como estratégia de intervenção usam os cabelos como ponto inicial para uma conversa sobre racismo e a forma de combatê-lo.

As intervenções do coletivo nas escolas são separadas, já que algumas abrangem desde o ensino fundamental ao médio. Com as crianças menores são tratados direitos e deveres a partir do Estatuto da Criança e do Adolescente (ECA) e literatura infanto-juvenil; e com as maiores, são realizadas oficinas abordando questões sobre afrocentricidade. Nas palavras de Karina Vieira, uma das integrantes do coletivo: "Discutimos questões centradas na nossa ancestralidade, as variadas faces do racismo, e sobre a prática do turbante para além da estética, como forma de reverência à ancestralidade e reconhecimento da negritude". [Depoimento, 11/08/2014]

Gomes (2003) ao discorrer como a identidade negra se articula com a cultura e a educação, diz:

Um caminho interessante para refletir sobre essa articulação seria não pensar a identidade negra como a única possível de ser construída pelos sujeitos que pertencem a esse grupo étnico/racial [...] Quando pensamos a articulação entre educação, cultura e identidade negra, falamos de processos densos, movediços e plurais, construídos pelos sujeitos sociais no decorrer da história, nas relações sociais e culturais. Processos que estão imersos na articulação entre o individual e o social, entre o passado e o presente, entre a memória e a história. (GOMES, 2003, p. 171)

Sabemos que, a escola não é o único espaço onde a educação acontece. Educar é muito mais amplo. Envolve uma dinâmica diária de ser, (com) viver, ensinar para aprender e aprender para ensinar que ultrapassa os muros da escola. Como bem aponta Brandão (1989, p.9): "Não há uma forma única nem um único modelo de educação; a escola não é o único lugar onde ela acontece e talvez nem seja o melhor; o ensino escolar não é a sua única prática e o professor profissional o seu único praticante". No entanto, recai sobre ela a institucionalização do saber. O que estamos querendo dizer com isso? Que a educação para as relações étnico- raciais deve estar presente nas práticas do cotidiano, dentro e fora da sala de aula, como exercício de uma prática educativa antirracista. Acreditamos que, ao trazer à tona a discussão e reflexão crítica sobre o racismo e na mesma tônica promover atitudes de 'não silenciamento', estamos assim contribuindo para e (na) superação do preconceito e discriminação.

Outra experiência a ser relatada no campo da educação é da Associação de Mulheres Negras Aqualtune. O coletivo se forma em 2007, da iniciativa de jovens mulheres negras atuantes no movimento negro e carentes de espaço para discutir as temáticas ligadas ao racismo, sexismo, homofobia e lesbofobia. O grupo é formado por jovens mulheres com diferentes formações acadêmicas. A partir de uma perspectiva mais plural e menos 
normatizadora, o coletivo tinha como objetivo, a construção de um grupo no qual fosse possível o convívio do saber acadêmico e do popular.

Sabemos que em nossa sociedade, muitas vezes, o imaginário social diante da diversidade, privilegia-se da visão dicotômica e binária. Um saber etnocêntrico que ignora outros conhecimentos. Sobre essa questão, podemos refletir diante da perspectiva de Candau (2009) ao dizer que:

Também na educação esta perspectiva tem se traduzido de diferentes maneiras, algumas mais sutis e outras mais explícitas. Está presente quando o fracasso escolar é atribuído a características sociais ou étnicas dos/as alunos/as; quando diferenciamos os tipos de escolas segundo a origem dos alunos e alunas, considerando que uns são melhores que os outros, têm maior potencial e para se desenvolver uma educação de qualidade não podem se misturar com sujeitos de menor potencial; quando como professores/as nos situamos diante dos/as alunos/as a partir de estereótipos e expectativas diferenciadas segundo a origem social e as características culturais dos grupos de referência; quando valorizamos exclusivamente o racional e desvalorizamos os aspectos emocionais presentes nos processos educacionais; quando privilegiamos somente a comunicação verbal, desconsiderando outras formas de comunicação humana como a corporal, a arte, etc. (CANDAU, 2009, p.73)

Neste sentido, o que se almejava era buscar o empoderamento através da atuação em espaços políticos de poder e também de uma grande e majoritária ação com as mulheres negras da comunidade e do entorno onde atuam.

Cada vez mais, os coletivos de diversos segmentos, vem adentrando no chão da escola e fazendo parcerias, a fim de ampliar as discussões em torno das diferenças. Com base nessas ações, o coletivo atua através de oficinas, valorizando uma metodologia pedagógica que prioriza a oralidade e corporeidade. As oficinas são realizadas em espaços como universidades, escolas, pré-vestibulares comunitários, ONG's e projetos sociais, privilegiando discussões e reflexões torno de temáticas sobre racismo, sexismo, violência doméstica e empoderamento de mulheres.

Os marcadores da desigualdade perpassa a história do Brasil e, consequentemente, da população negra. O que podemos destacar dessas duas experiências é o papel de promover um protagonismo educativo entre os sujeitos, valorizando a autoestima e principalmente a concepção de práticas pedagógicas alternativas ampliando o diálogo entre as instituições escolares e movimentos sociais.

A priori, o que pretendíamos nesse texto, era trazer à tona o tema das relações etnicorraciais, a partir de duas experiências de coletivos que vêm se efetivando ao longo desses últimos anos no campo da educação. A intencionalidade é não esgotar o tema, mas iniciar um debate futuro, em torno de práticas educativas e as possíveis mediações dentro e 
fora dos espaços da educação formal. A partir de alguns relatos aqui apresentados de jovens ativistas e suas práticas nos coletivos organizados, acreditamos que é necessário caminhar em busca de uma perspectiva de educação que se comprometa a descolonizar-se para (re)aprender e (re)ensinar através de um 'fazer outro'. Jessica, do coletivo Meninas Black Power ressalta: “A educação é a base para uma sociedade melhor, pois é na escola que aprendemos as coisas. Mas, historicamente, o que aprendemos lá é a reproduzir o racismo..."

O movimento de mulheres negras é um dos avanços mais importantes das últimas décadas do feminismo no Brasil, e as mulheres jovens têm contribuído para uma outra forma de se expressar culturalmente e educar, como por exemplo, um Hip Hop não machista, o reconhecimento da beleza negra e o resgate da autoestima da mulher negra.

\section{Algumas conclusões}

À guisa de conclusão, temos consciência que o caminho para a discussão em torno do protagonismo das mulheres negras numa perspectiva educativa (des) colonizadora vem crescendo através de pesquisas realizadas.

Ao nosso entender isso é um avanço, pois podemos pensar uma educação para alémfronteiras, valorizando diferentes saberes e sujeitos, em espaços formais e não formais. Partimos da afirmação que a preocupação por uma educação que respeite e valorize as diferenças culturais é hoje uma preocupação tanto de diferentes organismos internacionais, quanto de organizações governamentais, mas que teve mais forte impulso a partir da ação de atores da sociedade civil.

A inclusão do debate sobre raça nas escolas vai além do necessário reconhecimento dos direitos humanos dos afro-descendentes. O reconhecimento da diferença é a consciência da alteridade. É preciso que as diferenças sejam reconhecidas e respeitadas dentro da instituição escolar. Sendo assim, ao discutirmos relações raciais e gênero, podemos notar a força do discurso sobre a mulher negra em frases e comentários aparentemente inocentes, no entanto tão presentes no imaginário e nas práticas educativas dentro das escolas. Podemos citar, por exemplo, que, a estética da menina negra, seja por seu cabelo trançado, alisado ou crespo se torna alvo de práticas cruéis de meninas brancas e de meninos brancos e negros nas escolas.

O movimento de mulheres negras nos anos de 1980 e os que seguiram, tiveram um papel fundamental quando problematizaram a colonização do corpo e hegemonia estética a partir da branquidade que descaracterizava a identidade de outras mulheres. 
Quanto aos dois coletivos aqui apresentados, destacamos a importância de suas atuações no diálogo com a escola, uma vez que sabemos o quão difícil é estabelecer em algumas circunstâncias, ações que adentrem os muros da escola.

Ainda que não tenhamos acompanhado de perto o trabalho do coletivo para apurar quais os impactos dessas práticas educativas no comportamento dos alunos e alunas, consideramos que o fato de falar de racismo e buscar desfazer os 'silenciamentos' torna-se um caminho para refletir, combater, questionar as ações racistas que por ventura, possam acontecer dentro da escola. Seja na reprodução de práticas docentes ou entre os alunos/as.

Acreditamos que essas experiências já nos ajudam a pensar e apontar novas estratégias para aproximar movimentos sociais, coletivos organizados e escolas públicas na criação de práticas pedagógicas 'outras' contribuindo para um protagonismo educativo com bases antirracistas e antissexistas.

\section{Referências Bibliográficas}

ALMEIDA, Guilherme. Da invisibilidade à vulnerabilidade: percursos do "corpo lébico" na cena brasileira face À possibilidade de infecção por DST e AIDS. 2005. 307p. Tese (Saúde Coletiva) - Instituto de Medicina Social. Universidade do Estado do Rio de Janeiro, Rio de Janeiro. 2009.

BRANDÃO, Carlos. O que é educação. (Coleção Primeiros Passos). São Paulo: Brasiliense, 2007.

CANDAU, Vera Maria. Educação em Direitos Humanos e Diferenças Culturais: Questões e Buscas. Revista Múltiplas Leituras, v.2, n. 1, p. 65-82, jan. / jun. 2009.

CURIEL, Ochy. Una (auto)crítica ante nuestras luchas políticas de cara al racismo. Disponível em: http://www.lpp-uerj.net/olped/documentos/ppcor/0208.pdf. Acesso em 10 de junho de 2009.

GOMES, Nilma. Educação e identidade negra. Revista Aletria: alteridades em questão. Belo Horizonte, POSLIST/CEL, Faculdade de Letras da UFMG, v. 06, n.09, dez/2002, p.38-47. . Educação, identidade negra e formação de professores/as: um olhar sobre o corpo negro e o cabelo crespo. Educação e Pesquisa, São Paulo, v.29, n.1, p. 167-182, jan./jun. 2003.

LUCINDA, Maria da Consolação. Subjetividades e Fronteiras: Uma perspectiva etnográfica da manipulação da aparência. Dissertação - Universidade Federal do Rio de Janeiro, Museu Nacional. 2004. Antropologia Social. 
MIRANDA, Claudia. Currículos decoloniais e outras cartografias Para a educação das relações etnicorraciais: Desafios político-pedagógicos frente a lei $\mathrm{n}^{\circ} 10.639 / 2003$.

A prática de leitura de jovens universitárias do Movimento Negro Estudantil como estratégia de insurgência e de deslocamento. In: 17 Congresso de Leitura do Brasil, 2009, Campinas. 17 Congresso de Leitura do Brasil. Campinas, 2009.

MARCELINO, Sandra. Mulheres Negras Lésbicas: A fala rompeu o seu contrato e não cabe mais espaço para o silêncio. (Dissertação), PUC-Rio, 2011.

MARCELINO, Sandra. Trajetórias de mulheres negras lésbicas: a fala rompeu o seu contrato e o silêncio se desfez. In: FONSECA, Denise Pini Rosalem da; LIMA, Tereza Marques de Oliveira. (Org.). Outras Mulheres: mulheres negras brasileiras ao final da primeira década do

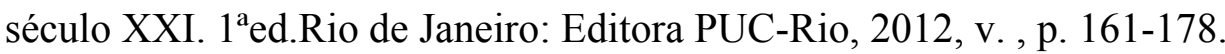

RIBEIRO, Matilde. Mulheres Negras Brasileiras: De Bertioga a Beijing. Revista de Estudos Feministas. 1995/2, ano 3, p. 446-456.

SANTOS, Luane Bento. "Para ficar bonita tem que sofrer!" A construção de identidade capilar para mulheres negras no Nível Superior (Monografia), UERJ, 2010.

http://observatoriodefavelas.org.br/noticias-analises/entre-a-visibilidade-e-a-invisibilidadeum-olhar-sobre-a-resistencia-da-mulher-negra-contemporanea/ entre a visibilidade e a invisibilidade: um olhar sobre a resistência da mulher negra contemporânea [Acesso em $11 / 08 / 2014]$

\footnotetext{
i PUC/Rio

ii Sobre isso, importa destacar o uso que Miranda $(2006 ; 2013)$ tem feito para situar os arranjos fomentados no processo de colonização europeia e partindo dos Estudos Pós-coloniais, reconhece, de um lado os estabelecidos (os que herdaram as vantagens da colonização) e do outro chamados "insurgentes" ( todos os grupos que estão fora desses espaços de prestígio e que foram racializados).

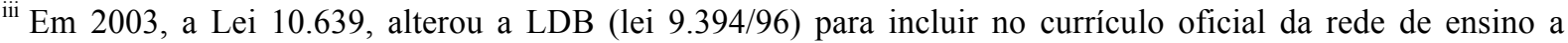
obrigatoriedade do estudo da história e cultura afro-brasileira. No ano de 2008, a Lei 11.645 alterou novamente a LBD para incluir no currículo a obrigatoriedade do estudo da história e cultura dos povos indígenas. Assim, a legislação passou a exigir a inclusão no currículo oficial da rede de ensino a obrigatoriedade do estudo da história e cultura afro-brasileira e indígena.

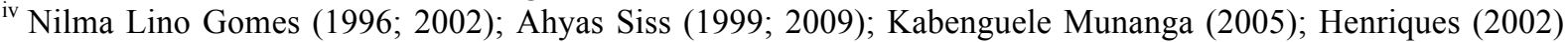
Cavalleiro (2000).

${ }^{\vee} \mathrm{O}$ evento tem por como objetivo empoderar a população negra através de palestras sobre estéticas, empreendedorismo, artesanatos, literatura voltados para a cultura afro-brasileira.
} 